\title{
The tail domain of PRRSV NSP2 plays a key role in aggrephagy by interacting with $14-3-3 \varepsilon$
}

\author{
Shengliang Cao ${ }^{1,2,3}$, Jiaqi Liu1, 1,2,3, Guofei Ding 1,2,3, Qingyuan Shao 1,2,3, Bin Wang 1,2,3, Yingchao Li ${ }^{1,2,3}$, \\ Jian Feng ${ }^{1,2,3}$, Yuzhong Zhao ${ }^{1,2,3}$, Sidang Liu ${ }^{1,2,3^{*}}$ and Yihong Xiao ${ }^{1,2,3^{*}}$ (D)
}

\begin{abstract}
Porcine reproductive and respiratory syndrome (PRRS) caused by PRRS virus (PRRSV) is one of the most severe swine diseases that affects almost all swine-breeding countries. Nonstructural protein 2 (NSP2) is one of the most important viral proteins in the PRRSV life cycle. Our previous study showed that PRRSV NSP2 could induce the formation of aggresomes. In this study we explored the effects of aggresome formation on cells and found that NSP2 could induce autophagy, which depended on aggresome formation to activate aggrephagy. The transmembrane and tail domains of NSP2 contributed to aggrephagy and the cellular protein 14-3-3E played an important role in NSP2-induced autophagy by binding the tail domain of NSP2. These findings provide information on the function of the C-terminal domain of NSP2, which will help uncover the function of NSP2 during PRRSV infection.
\end{abstract}

Keywords: PRRSV, NSP2, Aggrephagy, 14-3-3e, Tail domain of NSP2

\section{Introduction}

Porcine reproductive and respiratory syndrome (PRRS) caused by PRRS virus (PRRSV) is one of the most severe swine diseases and is responsible for substantial economic losses [1]. According to the OIE database (https:// www.oie.int/wahis_2/public/wahid.php/Diseaseinformat ion/Diseasetimelines), 64 of 210 countries or areas have reported PRRSV infections, including China, European Union, the United States of America, Canada, and Russia, which were among the top 10 pork-producing countries. It is estimated that the economic impact of PRRSV on pork producers in the United States alone is more than $\$ 560$ million annually [2].

PRRSV is an enveloped single-stranded positive sense RNA virus belonging to the family Arteriviridae and order Nidovirales. The classification of PRRSV is updated recently and divided into two species to accommodate

\footnotetext{
*Correspondence: Liusid@sdau.edu.cn; xiaoyihong01@163.com ${ }^{1}$ Department of Fundamental Veterinary Medicine, College of Animal Science and Veterinary Medicine, Shandong Agricultural University, 61 Daizong Street, Tai'an 271018, Shandong, China

Full list of author information is available at the end of the article
}

the clear divergence of the European type (PRRSV-1) and American type (PRRSV-2) [3]. The PRRSV genome is $\sim 15 \mathrm{~Kb}$ with 11 open reading frames (ORFs) encoding 14 nonstructural proteins and eight structural proteins [4-7]. Two polyproteins, PP1a and PP1ab, are encoded by ORF1a and ORF1b, respectively, and are processed into at least 14 nonstructural proteins (NSPs) by four ORF1aencoded proteinases called NSP1 $\alpha$, NSP1 $\beta$, NSP2, and NSP4 [8-11]. NSP2 is the largest product, and contains a cysteine protease (PL2) domain, a central hypervariable (HV) domain, and a transmembrane (TM) domain followed by a tail domain $[11,12]$.

The PL2 domain is a member of the ovarian tumor (OTU) protease superfamily and is responsible for the cleavage of PP1a between NSP2 and NSP3 [13, 14]. This domain also exhibits deubiquitinating and interferonantagonism functions, and inhibits the antiviral function of interferon-stimulated gene 15 to block innate antiviral responses [15-17]. The HV domain is the most variable domain in the viral genome. Mutations, insertions, and deletions occur in this domain, which affects the overall length of the genome [18-20].

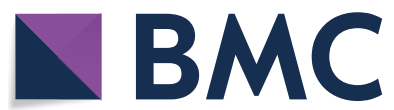

(c) The Author(s) 2020. This article is licensed under a Creative Commons Attribution 4.0 International License, which permits use, sharing, adaptation, distribution and reproduction in any medium or format, as long as you give appropriate credit to the original author(s) and the source, provide a link to the Creative Commons licence, and indicate if changes were made. The images or other third party material in this article are included in the article's Creative Commons licence, unless indicated otherwise in a credit line to the material. If material is not included in the article's Creative Commons licence and your intended use is not permitted by statutory regulation or exceeds the permitted use, you will need to obtain permission directly from the copyright holder. To view a copy of this licence, visit http://creativeco mmons.org/licenses/by/4.0/. The Creative Commons Public Domain Dedication waiver (http://creativecommons.org/publicdomain/ zero/1.0/) applies to the data made available in this article, unless otherwise stated in a credit line to the data. 
The highly pathogenic and NADC30-like PRRSV-2 emerged in China in 2006 and 2013 and contained deletions of 30 and 131 amino acids in the NSP2 gene, respectively [21-23]. Most concerning was the emergence of a recombinant PRRSV-2 between the HP-PRRSV and NADC30-like strains in the HV domain of NSP2 [24-26]. It was recently reported that the HV domain is associated with viral cellular tropism to primary porcine alveolar macrophages and contributes to targets of neutralizing antibodies $[27,28]$. Little information is available on the TM and tail domains.

In eukaryotic cells, protein aggregates formed by incorrectly folded proteins are delivered to the microtubule organizing center (MTOC) along microtubules via dynein-dependent retrograde transport [29]. When the degradative capacity of proteasomes is exceeded, protein aggregates accumulate in perinuclear inclusions called aggresomes [30, 31]. Viral infections always produce large amounts of viral proteins that cannot be folded and form an aggresome. Aggresomes are thought to provide a physical scaffold to concentrate viral components and thereby increase the efficiency of replication [32]. Viruses use different strategies to make full use of aggresomes during their life cycle. For example, influenza A virus uses the aggresome-processing machinery for host-cell entry [33], while Asfarvirus, iridoviruses, poxviruses, retroviruses, and herpesviruses use aggresomes as virus assembly sites to facilitate replication and assembly [32, $34,35]$. Virus-infected cells always evoke autophagy to degrade the aggresomes for self-protection. This process is called aggrephagy [31, 36, 37].

Our previous study showed that PRRSV-2 NSP2 could induce the formation of aggresomes [38, 39], a process in which cellular protein 14-3-3 played a role. It has been confirmed that PRRSV-2 infections can induce autophagy to facilitate infection [40-43]. These findings raised the questions of whether autophagy caused by PRRSV-2 is induced by the NSP2 aggresome and what the role of 14-3-3 is during this process.

\section{Materials and methods}

\section{Cell culture and viruses}

293T cells (human embryo kidney cells), Marc-145 cells (PRRSV-susceptible cell line derived from African monkey kidney), BHK21 cells (baby hamster Syrian kidney), and Vero E6 cells (African green monkey kidney cells) were obtained from the China Center for Type Culture Collection (Wuhan, China). Cells were cultured in Dulbecco's modified Eagle's medium (DMEM; Gibco Invitrogen, Carlsbad, CA, USA) supplemented with $10 \%(\mathrm{v} / \mathrm{v})$ fetal bovine serum (FBS; Biological Industries, Beit HaEmek, Israel) and $1 \%(\mathrm{v} / \mathrm{v})$ penicillin-streptomycin (Solarbio Life Science, Beijing, China). All cells were grown at
$37{ }^{\circ} \mathrm{C}$ in a humidified incubator with $5 \% \mathrm{CO}_{2}$. A highpathogenic PRRSV-2 (HP-PRRSV) strain (strain TA-12; GenBank No. HQ416720) was preserved by our team. A low-pathogenic PRRSV-2 (LP-PRRSV) strain, CH-1R, was kindly provided by Professor Enmin Zhou (Northwest A\&F University, China).

\section{Plasmids and transfections}

The full-length and truncated NSP2 genes were cloned into pEGFP-C1 vector which was tagged by green fluorescent protein (GFP), and GFP-NSP2, OTU-GFP (aa 47-159), HV-GFP (aa 160-844), TM-GFP (aa 845-1018), and Tail-GFP (aa 1019-1194) were generated as previously described [38]. FLAG-NSP2 was generated using the pCDNA3.0-FLAG vector by inserting NSP2 between the BamH I and Not I restriction sites. The NSP3 gene of TA-12 was cloned into pEGFP-C1 using Bgl II and Hind III restriction sites to generate GFP-NSP3. The PDsRed2C1-LC3 plasmid was kindly provided by Jiuqiang Wang (Institute of Zoology, Chinese Academy of Sciences). The mutant plasmids for NSP2-Tail were generated via PCR and harbored mutations encoding the substitutions R991K and A994E (numbered according to the NSP2 sequence of HP-PRRSV strain TA-12), and named KTAP and RTEP, respectively. NSP2-Tail without mutations was referred to as the wild type (WT).

Transfections were performed using X-tremeGENE HP DNA transfection reagent (Roche Applied Science, Basel, Switzerland) according to the manufacturer's instructions. Then new DMEM complete medium containing 10\% FBS was replaced before transfection. Cells were collected for Western blot analyses at 12-36 h after transfection.

\section{Antibodies and reagents}

Antibodies and their manufacturers were as follows: anti$\beta$-actin (AP0060; Bioworld Technology, St. Louis Park, MN, USA), anti- $\alpha$ glyceraldehyde 3-phosphate dehydrogenase (GAPDH) (1:5000) (AT0002; CMCTAG, Dover, DE, USA), anti-GFP (1:5000) (AT0028; CMCTAG), antiFLAG (1:5000) (AT0022; CMCTAG), anti-LC3 (1:3000) (L7543; Sigma-Aldrich), anti-p62 (1:5000) (P0067; SigmaAldrich), and anti-14-3-3e (1:800) (sc-23957; Santa Cruz Biotechnology, Santa Cruz, CA, USA). Anti-NSP2 antibodies were prepared by immunizing New Zealand white rabbits with a recombinant protein composed of the N-terminal 180 amino acids of NSP2 (NSP2-180). The monoclonal antibody against PRRSV-2 nucleocapsid (N) protein 6D10 was prepared in our laboratory [44]. Horseradish-peroxidase-conjugated anti-mouse or anti-rabbit secondary antibodies were purchased from Jackson Laboratories (1:5000) (West Grove, PA, USA). 
Complete $^{\mathrm{TM}}$ protease inhibitor cocktail (04693132001) was purchased from Roche (Basel, Switzerland), the aggresome detection kit (ab139486) was purchased from Abcam (Cambridge, UK), and nocodazole (M1404) and MG132 (C2211) were obtained from Sigma-Aldrich.

\section{Confocal fluorescence microscopy}

Marc-145 cells, 293T cells, and Vero E6 cells were seeded onto coverslips in 24-well plates and transfected with plasmids using X-tremeGENE HP DNA transfection reagent (Roche, Basel, Switzerland). Marc-145 cells were either mock infected or infected with TA-12 or CH-1R at a multiplicity of infection of 0.01 . Cells were harvested at the indicated time points and fixed with $4 \%$ paraformaldehyde (Beyotime Biotech, Shanghai, China) for $15 \mathrm{~min}$. They were then permeabilized with $0.1 \%$ Triton X-100 (Solarbio Life Science) in phosphate-buffered saline (PBS) for $15 \mathrm{~min}$, and blocked with $1 \%$ bovine serum albumin (BSA; Solarbio Life Science) in PBS for $1 \mathrm{~h}$. After washing three times with PBS, cells were incubated with primary antibodies or aggresome detection reagent diluted in PBS for $2 \mathrm{~h}$. Cells were then washed and incubated with fluorescently-labeled secondary antibodies conjugated to fluorescein isothiocyanate or Cy3. Cell nuclei were stained with 4',6-diamidino-2-phenylindole (DAPI; Invitrogen). All laser scanning images were obtained using a fluorescence microscope (Leica, SPE, Buffalo Grove, IL, USA).

\section{Transmission electron microscopy}

$293 \mathrm{~T}$ cells were transfected with GFP-NSP2 and pEGFP$\mathrm{C} 1$ plasmids. Following transfection for $24 \mathrm{~h}$, cells were harvested and centrifuged in clean $2-\mathrm{mL}$ round-bottomed centrifuge tubes. After washing with ice-cold PBS twice, cells were pelleted and fixed in fresh ice-cold $3 \%$ glutaraldehyde. Samples were rinsed, fixed with $1 \%$ osmium tetroxide $\left(\mathrm{OsO}_{4}\right)$, rinsed again, dehydrated, impregnated, and embedded in Epon812 resin (Electron Microscopy Sciences, Hatfield, PA, USA) according to conventional transmission electron microscopy (TEM) sample preparation procedures. The processed samples were then sectioned using an LKB-V ultra-thin microtome and stained with uranyl acetate and lead citrate. Sections were observed using a transmission electron microscope (JEOL-1200EX; JEOL, Tokyo, Japan) and recorded using an electron microscope (MORADAG2; EMSIS GmbH, Münster, Germany).

\section{GFP pull-down assays and Western blot analysis}

Cells in 10-cm dishes were transfected with either empty vector, WT NSP2-Tail-GFP (WT), or EGFP-tagged NSP2-Tail mutant plasmid (RTEP or KTAP), with four dishes per plasmid. Cells harvested at $24 \mathrm{~h}$ after transfection were extracted in ice-cold lysis buffer (10 mM Tris/
$\mathrm{HCl}, \mathrm{pH}$ 7.5, $150 \mathrm{mM} \mathrm{NaCl}, 0.5 \mathrm{mM}$ EDTA, 0.5\% NP-40) supplemented with Complete ${ }^{\mathrm{TM}}$ protease inhibitor cocktail (Roche) for $30 \mathrm{~min}$ on crushed ice and then centrifuged at $20,000 \times g$ for $20 \mathrm{~min}$ at $4{ }^{\circ} \mathrm{C}$. For GFP pull-down assays, whole-cell extracts were incubated with equilibrated GFP-trap beads for $5 \mathrm{~h}$ at $4{ }^{\circ} \mathrm{C}$ (gta-20; Beijing Lab, Beijing, China). After centrifugation at $2500 \times g$ for $2 \mathrm{~min}$ at $4{ }^{\circ} \mathrm{C}$, the beads were washed three times with dilution buffer $(10 \mathrm{mM}$ Tris/ $\mathrm{HCl}, \mathrm{pH} 7.5,150 \mathrm{mM} \mathrm{NaCl}$, $0.5 \mathrm{mM}$ EDTA) supplemented with Complete ${ }^{\mathrm{TM}}$ protease inhibitor cocktail. Precipitated proteins were eluted with $100 \mu \mathrm{L}$ of $5 \times$ sodium dodecyl sulfate (SDS) loading buffer by boiling at $95^{\circ} \mathrm{C}$ for $6 \mathrm{~min}$.

Marc-145, 293T, and BHK21 cells were lysed in RIPA buffer (P0013B; Beyotime, Shanghai, China) supplemented with protease inhibitor cocktail (CW2200, CWBIO, Beijing, China). Protein concentrations were measured with a Pierce ${ }^{\mathrm{TM}}$ BCA protein assay kit (23227; ThermoFisher, Shanghai, China).

Equal amounts of precipitated protein or cell lysates were resolved using $10 \%$ or $12 \%$ SDS-polyacrylamide gel electrophoresis and then transferred to a polyvinylidene difluoride (PVDF) membrane (Millipore Corporation, Bedford, MA, USA) using a Bio-Rad Trans-Blot apparatus (Bio-Rad Laboratories, Hercules, CA, USA) and standard procedures. PVDF membranes were blocked with 5\% (W/V) BSA in PBST (PBS with 1\% Tween-20) for $1 \mathrm{~h}$ at room temperature, and probed with the indicated primary antibodies in blocking buffer at $4{ }^{\circ} \mathrm{C}$ overnight. Following overnight incubation with primary antibodies, membranes were incubated for $1 \mathrm{~h}$ with appropriate horseradish-peroxidase-conjugated anti-mouse or antirabbit secondary antibodies. Proteins were visualized using the Clarity ${ }^{\mathrm{TM}}$ Western ECL substrate (170-5060; Bio-Rad Laboratories) and detected using a Western blot fluorescence imager (Vilber Fusion FX7; Vilber Lourmat, Collégien, France). The density of the protein bands was measured using Fusion analysis software in the Vilber Fusion FX7 imaging system. Band densities were determined after subtracting the density of the GAPDH or $\beta$-actin bands.

\section{Nocodazole toxicity analysis and treatment}

Cytotoxicity was measured using the Cell Counting Kit-8 (CCK-8) assay (TransGen Biotech, Beijing, China) according to the manufacturer's instructions. Marc-145 cells and 293T cells were seeded at a density of $5 \times 10^{3}$ cells per well in complete medium in 96-well plates. After $12 \mathrm{~h}$ of culture, nocodazole was added to each well at specific concentrations and incubated for $48 \mathrm{~h}$ at $37{ }^{\circ} \mathrm{C}$. Dimethyl sulfoxide-treated cells were included as controls. After treatment, the medium was removed and changed to $100 \mu \mathrm{L}$ of PBS containing $10 \%$ CCK- 8 
solution. After incubation for $2 \mathrm{~h}$ at $37{ }^{\circ} \mathrm{C}$, cell viability was detected by measuring the absorbance at $450 \mathrm{~nm}$ using a microplate reader (Bio-Rad model 680). The above experiment was repeated three times.

After infection with PRRSV-2, Marc-145 cells were incubated in maintenance medium containing 0.08, 0.16 , or $0.32 \mu \mathrm{g} / \mathrm{mL}$ nocodazole for $24 \mathrm{~h}$, and then harvested for Western blot analysis. 293T cells were transfected with pEGFP-C1 and GFP-NSP2 plasmids for $6 \mathrm{~h}$. The cells were incubated with different concentrations of nocodazole $(0.08,0.16$, and $0.32 \mu \mathrm{g} / \mathrm{mL})$ for $4 \mathrm{~h}$, and then collected at $24 \mathrm{~h}$ after transfection for Western blot analysis. 293T cells were also incubated with $0.32 \mu \mathrm{g} / \mathrm{mL}$ nocodazole for $4 \mathrm{~h}$, and then collected at different time points for Western blot analyses.

\section{Statistical analysis}

Statistical analysis was performed using the SPSS 23.0 software package (SPSS Inc., version 23.0; Chicago, IL, USA). All data are expressed as the mean \pm standard deviation (SD) from at least three biological replicates (n) for each condition. Statistical differences between groups were assessed using Student's $t$ test. $P$-values less than 0.05 were considered to indicate a statistically significant difference $\left({ }^{*} P<0.05,{ }^{* *} P<0.01\right.$, and $\left.{ }^{* * * *} P<0.001\right)$.

\section{Results}

\section{NSP2 can induce autophagy}

Autophagy is a defense mechanism for clearance of toxic proteins, including viral proteins. However, autophagymediated clearance of aggresome-like inclusions is a selective phenomenon [45]. To determine whether NSP2induced aggresomes could induce autophagy, we firstly studied whether NSP2 could mediate autophagy. Fulllength NSP2 with GFP or FLAG tags was expressed in $239 \mathrm{~T}$ or BHK21 cells. Western blot results revealed that the LC3-II/LC3-I ratio increased in the NSP2-expressing cells, while p62 levels decreased (Figure 1A). Electron microscopy analyses also revealed a double membranebound compartment in 293T cells expressing NSP2 (Figure 1B). NSP2 also co-localized with LC3 (Figure 1C). Taken together, these findings indicate that NSP2 could induce autophagy.

\section{NSP2-induced autophagy depends on aggresome formation}

Aggresomes are the perinuclear inclusion bodies formed around the MTOC by active minus-end-directed transport of misfolded proteins on microtubules [32]. To further confirm the relationship between NSP2-induced autophagy and NSP2-induced aggresomes, nocodazole, which induces microtubule depolymerization, was used as an inhibitor of aggresome formation. The cytotoxicity of nocodazole was confirmed by CCK- 8 assays (Figure 2A). 293T cells were transfected with GFP-NSP2 or empty vector and then treated with $0.08,0.16$, or $0.32 \mu \mathrm{g} /$ $\mathrm{mL}$ nocodazole. The results revealed that the LC3-II/ LC3-I ratio was reduced while the level of p62 increased in a dose-dependent manner (Figure 2B). 293T cells were transfected with GFP-NSP2 and then treated with $0.32 \mu \mathrm{g} / \mathrm{mL}$ nocodazole. Cells were collected at 12,24 , and $36 \mathrm{~h}$ after transfection for western blot analysis. The western blot results also revealed that the LC3-II/LC3-I ratio was decreased, while levels of p62 increased (Figure $2 \mathrm{C}$ ). These results show that disruption of aggresomes could decrease autophagy. To further confirm this finding, Marc-145 cells were infected with TA-12 and treated with nocodazole. The results showed that the LC3-II/ LC3-I ratio and p62 levels were decreased compared to untreated cells (Figure 2D). All these results showed that NSP2-induced autophagy depends on aggresome formation to activate aggrephagy.

\section{The TM and tail domains of NSP2 contribute to aggresome formation}

Our previous studies revealed that NSP2 can induce the formation of aggresomes [38]. To further confirm the formation of aggresomes, Marc-145 cells were infected with TA-12 or the LP-PRRSV strain. Both strains co-localized with aggresomes (Figure $3 \mathrm{~A}$ ).

NSP2 contains OTU, HV, TM, and tail regions. To test which region(s) contribute to the formation of aggresomes, NSP2 constructs containing the four gene fragments were transfected into Vero E6 and 293T cells. The TM and tail regions had a dotted appearance under confocal microscopy and co-localized with aggresomes in cells (Figure 3B).

The TM and tail domains of NSP2 contribute to aggrephagy Marc-145 cells were infected with TA-12 and CH-1R strains, respectively. The results revealed that both viruses could co-localize with aggresomes. Thus, to test which region(s) of NSP2 contribute to autophagy, the truncated constructs were transfected into 293T cells and whole-cell lysates were analyzed by western blot. The results show that the tail and TM domains of NSP2 could induce an increase in the LC3-II/LC3-I ratio and a reduction in p62 levels (Figure 4A). The TM and tail domains appeared as dotted particles and co-localized with LC3 (Figure 4B). Taken together, these results 


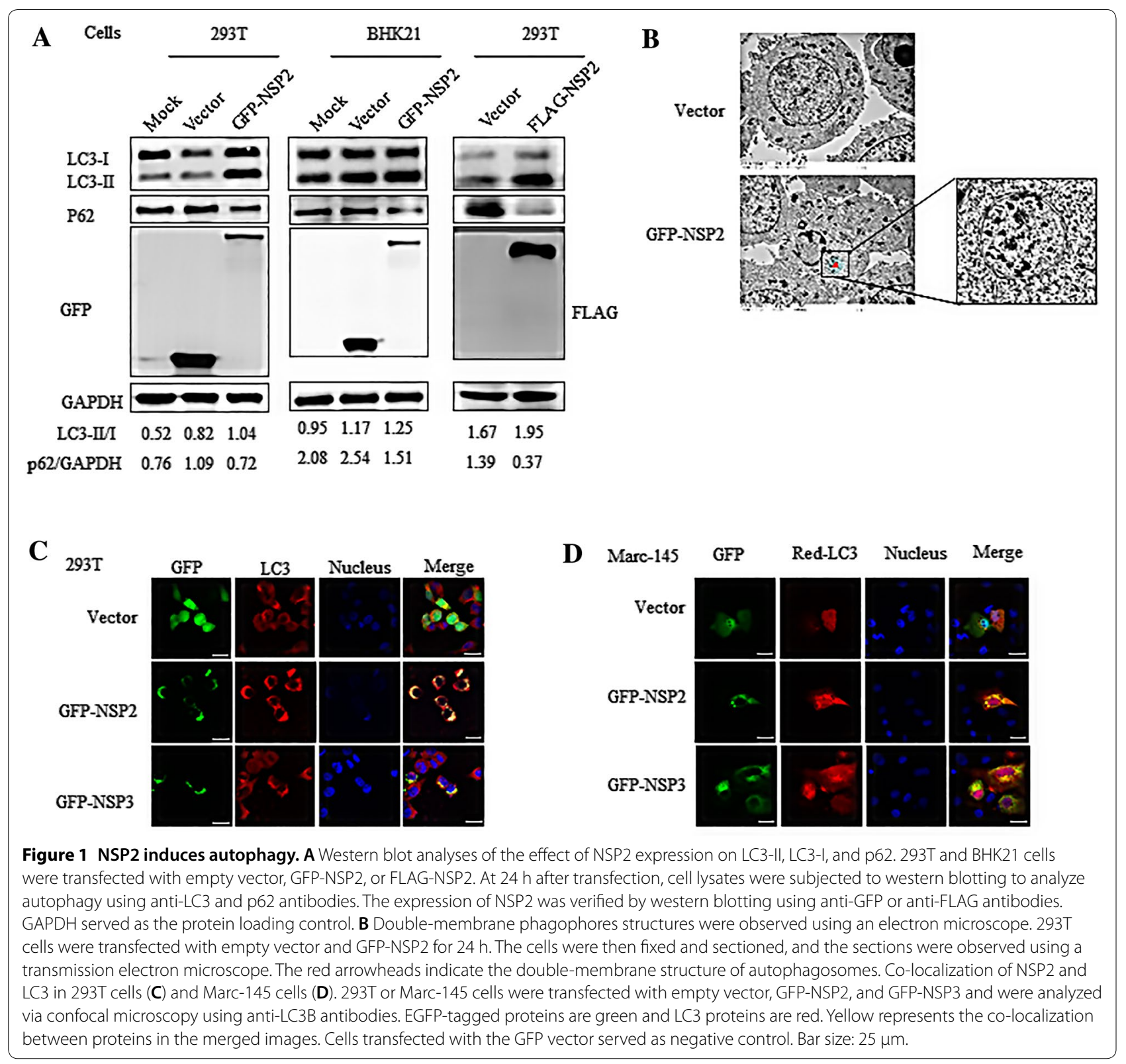

indicate that the TM and tail domain of NSP2 contribute to aggrephagy.

The tail of NSP2 induces autophagy by binding 14-3-3ع $14-3-3 \varepsilon$ is a multifunctional protein involved in innate immunity, protein trafficking, cancer development, aggresome formation, and other activities [34]. We previously reported that NSP2 interacts with $14-3-3 \varepsilon$ to promote the formation of aggresomes. Thus, the role of $14-3-3 \varepsilon$ in NSP2-induced autophagy was investigated. First, the interaction between $14-3-3 \varepsilon$ and NSP2 truncations was studied and the results revealed colocalization of $14-3-3 \varepsilon$ and the tail domain of NSP2 (Figure 5A). To further confirm an interaction between the two proteins, GFP pull-down assays were performed and the results show that $14-3-3 \varepsilon$ was immunoprecipitated by the NSP2 tail region (Figure $5 \mathrm{~B}$ ). On the 


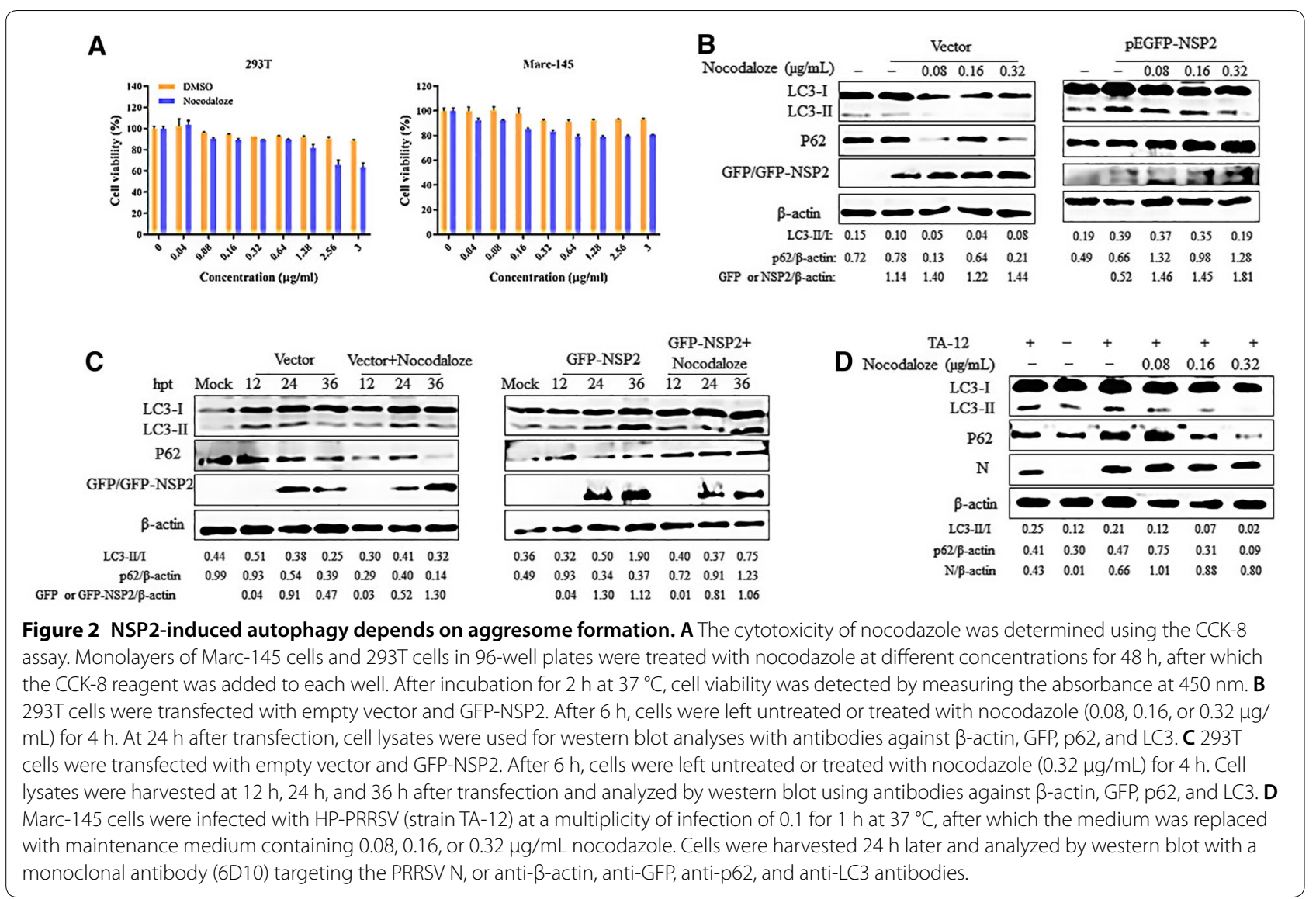

basis of these results, we focused on the role of $14-3-3 \varepsilon$ in aggrephagy caused by the NSP2 tail region.

It has been reported that $14-3-3 \varepsilon$ binds NS3 of dengue virus through the RIEP motif [46]. A similar ${ }^{991}{ }^{\text {RTAP }}{ }^{994}$ motif is also found in the tail region of NSP2. Thus, two mutant plasmids of KTAP (R991K) and RTEP (A993/E) were constructed. RTEP could bind $14-3-3 \varepsilon$ with similar affinity to WT (RTAP), while the binding of KTAP to $14-3-3 \varepsilon$ was greatly decreased (Figure $5 B$ ). These results reveal that the $\mathrm{R}$ in the RTAP motif plays a key role in binding between the NSP2 tail domain and 14-3-3e. The mutant plasmids were then transfected into 293T cells. Western blots revealed that expression of KTAP decreased the LC3-II/LC3-I ratio and increased the level of p62. Conversely, expression of RTEP increased the LC3-II/LC3-I ratio and decreased the level of p62, similar to the findings for expression of the WT tail. Thus, these results show that $14-3-3 \varepsilon$ could promote the occurrence of autophagy.

\section{Discussion}

Substantial evidence has confirmed that PRRSV-2 infection induces autophagy to promote viral replication [41$43,47]$, but there is little information on the mechanisms via which this occurs. In this study, we found that NSP2 can induce autophagy which depends on the aggresome formation. NSP2 is a multifunctional protein with a complex structure. The size of NSP2 cleavage products varies between PRRSV-2 strains because of variable cleavage sites at its $\mathrm{C}$-terminus. This variability in cleavage sites explains the differing and sometimes contradictory functions of NSP2. However, strong proof has been established for cleavage sites at or near the G1196/G1197 dipeptide (numbered according to the NSP2 sequence of PRRSV-2 strain VR-2332) [5, 11, 12]. In this study, NSP2 containing 1166 amino acids (1-1166, numbered according to the NSP2 sequence of HP-PRRSV strain TA-12) was used to study its function. Cells have evolved the ability to accommodate different types of protein inclusions by targeting them for clearance via different autophagy pathways [48]. As foreign inclusions, virus particles and viral proteins are often aggregated in cells. The presence of large amounts of viral proteins in cells results in the formation of aggresomes, which are then selectively degraded via autophagy [37]. We found that NSP2 can induce the formation of aggresomes.

To determine whether NSP2-induced aggresomes are degraded via autophagy, we first studied the relationship 

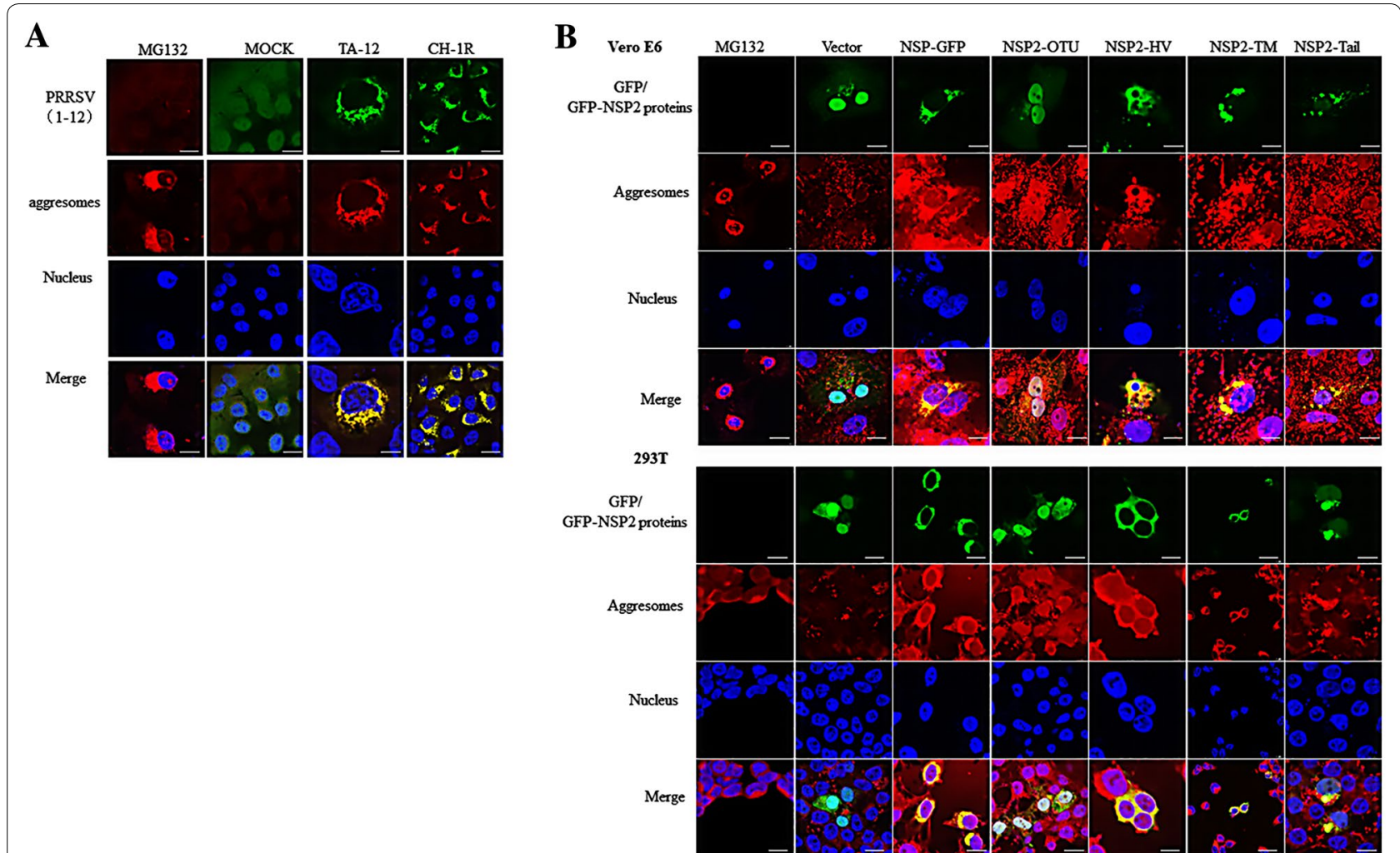

Figure 3 TM and tail domains of NSP2 co-localize with aggresomes. A Confocal microscopy of Marc-145 cells mock infected or infected for $24 \mathrm{~h}$ with TA-12 and $\mathrm{CH}-1 \mathrm{R}$ at a multiplicity of infection of 0.01 (left margin), then stained for PRRSV (green) with anti-NSP2 antibodies and aggresomes (red) with aggresome detection reagent. The nucleus was stained with the DNA-binding dye DAPI (blue). Before harvesting, positive controls were set by incubation with diluted proteasome inhibitor (MG-132, $5 \mu \mathrm{M}$ ) for $18 \mathrm{~h}$ under normal cell culture conditions. B $293 \mathrm{~T}$ and Vero E6 cells were transfected with NSP2-GFP, OTU-GFP, HV-GFP, TM-GFP, Tail-GFP, and empty vector (green). At $24 \mathrm{~h}$ later, cells were fixed and stained with aggresome detection reagent (red). The treatment method for positive cells is shown in (A). Yellow in the merged images represents the formation of aggresomes. Bar size: $25 \mu \mathrm{m}$.

between NSP2 and autophagy. On the basis of changes in the LC3-II/LC3-I ratio and levels of p62, as well as co-localization of LC3 and NSP2 and the appearance of double-membrane phagophores (Figure 1), we concluded that NSP2 can induce autophagy.

To determine whether NSP2-induced autophagy is dependent on the formation of aggresomes, we used nocodazole to inhibit the formation of aggresomes. The results show that nocodazole can inhibit NSP2-induced autophagy, which implies that the process depends on the formation of aggresomes (Figure 2). Thus, PRRSV-2 can induce aggresome formation (Figure 3 ) via expression of NSP2.

Addition of nocodazole to PRRSV-2 -infected Marc145 cells significantly decreased the LC3-II/LC3-I ration and levels of p62. These findings are contradictory to those found during PRRSV-2 -induced autophagy. Multiple viral proteins are produced during
PRRSV-2 infection and the decrease in p62 levels could be related to blocking of autophagy due to cleavage of NSP2 protein, together with other autophagy proteins, by caspases or viral proteases [49]. As mentioned above, NSP2 contains four domains. To determine which domain(s) contribute to the induction of aggrephagy, four truncated NSP2 constructs were transfected into cells. Subsequent experiments revealed that the TM and tail domains participate in the formation of aggrephagy (Figure 4). The precise domain(s) of NSP2 that induce autophagy were also investigated. The results also indicate that the TM and tail domains can induce autophagy (Figure 3). Taken together, the results indicate that the TM and tail domains of NSP2 can induce aggrephagy.

The 14-3-3 proteins are a family of conserved regulatory molecules that can bind a multitude of functionally diverse signaling proteins, including kinases, 


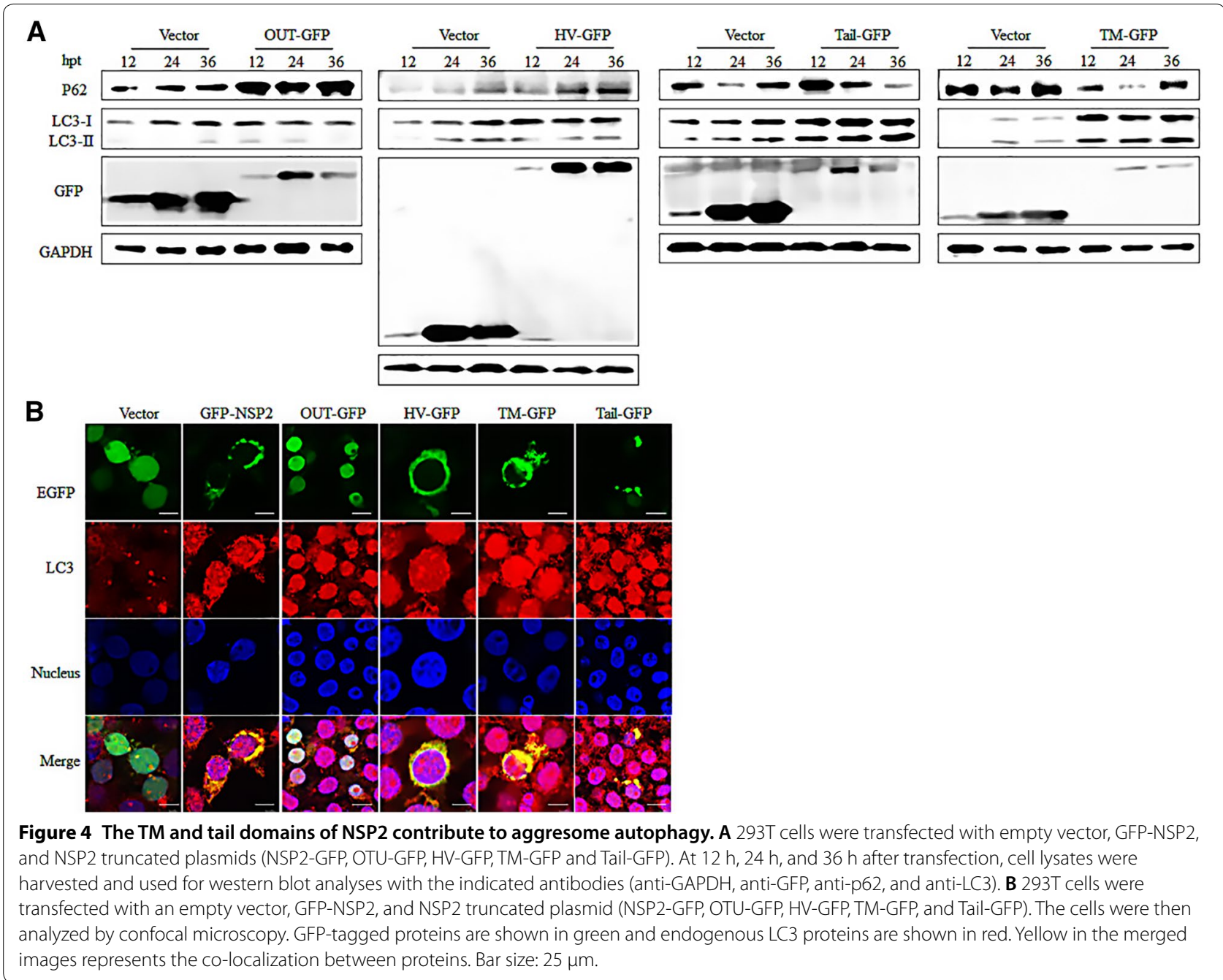

phosphatases, and TM receptors. Of seven isoforms, $14-3-3 \varepsilon$ interacts with viral proteins and plays a role in the innate immune response induced by viral infections [38, 50-53]. Our previous study showed that 14-3-3 interacts with NSP2 and that $14-3-3 \varepsilon$ acts as a proviral factor during HP-PRRSV infection [39]. Thus, the specific domain(s) of NSP2 that interact with $14-3-3 \varepsilon$ were investigated using co-localization assays. The results revealed that the $\mathrm{HV}$ and tail domains co-localize with $14-3-3 \varepsilon$ (Figure $5 \mathrm{~A}$ ). As the TM and tail domains of NSP2 can induce aggrephagy, interaction of the tail domain with $14-3-3 \varepsilon$ was investigated (Figure $5 B$ ). The ${ }^{991}$ RTAP $^{994}$ motif, which is similar to the NS3 domain of dengue virus, was identified in the tail domain of NSP2 [46]. To confirm the specific amino acids that contribute in the interaction between $14-3-3 \varepsilon$ and the tail domain, R991K and A993/E mutations were introduced into the RTAP motif. These experiments revealed that the $\mathrm{R} 991 \mathrm{~K}$ mutant decreased the interaction and autophagy. The results also indicate that $14-3-3 \varepsilon$ can bind the ${ }^{991}$ RTAP $^{994}$ motif to promote autophagy. Thus, PRRSV-2 induces autophagy to facilitate infection, which may imply that $14-3-3 \varepsilon$ functions as a proviral factor.

In vitro, primary pig macrophages (e.g. alveolar macrophages), African green monkey kidney derived cells, such as Marc-145 or modified cell lines are susceptible for the production of PRRSV [54, 55]. In this study, 293T, BHK21, Vero E6 cells were employed, while no results were showed on the alveolar macrophages or other types of swine-originated cell lines because of their hardness to be transfected.

In conclusion, NSP2 can induce aggrephagy and the $\mathrm{C}$-terminal domain contributes to this process. The tail domain of NSP2 plays a key role in inducing aggrephagy 


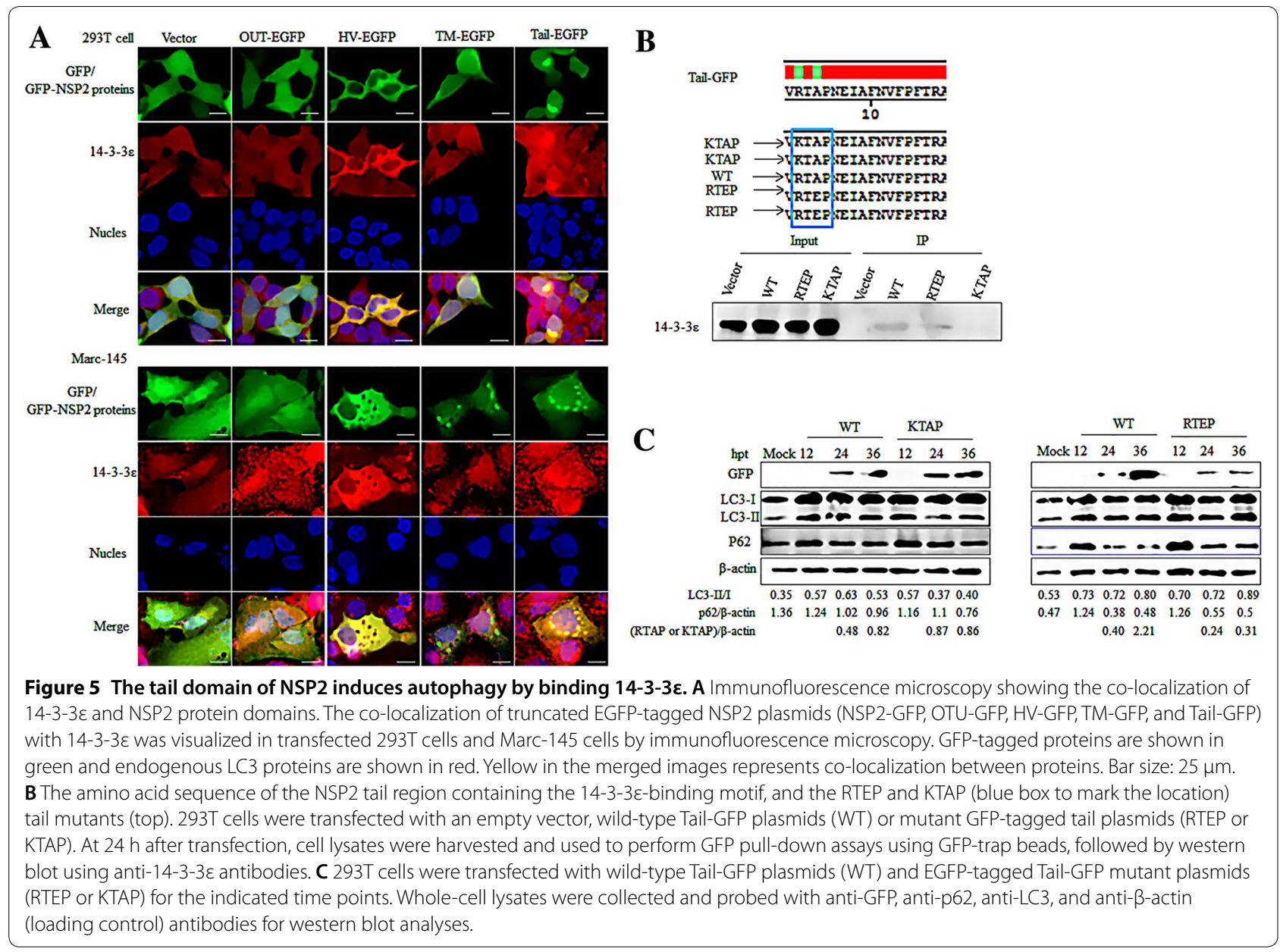

by binding 14-3-3e. These findings provide information on the function of the C-terminal domain of NSP2.

\section{Acknowledgements}

This work was supported by the National Natural Science Foundation of China (Grant Number 31772708), the National Key Research and Development Program of China (Grant Numbers 2016YFD0500201 and 2017YFD0501000), and the Funds of Shandong "Double Tops" Program.

\section{Authors' contributions}

$S C, J L, G D, Q S$, and $Y X$ conducted the research and interpreted the results. $S C, J L, B W, J F, Y L, Y Z$, and $Y X$ participated in data collection. SC, GD, SL, and $Y X$ contributed to data analysis and helped draft the manuscript. All authors read and approved the final manuscript.

\section{Competing interests}

The authors declare that they have no competing interests.

\section{Author details}

${ }^{1}$ Department of Fundamental Veterinary Medicine, College of Animal Science and Veterinary Medicine, Shandong Agricultural University, 61 Daizong Street, Tai'an 271018, Shandong, China. ${ }^{2}$ Shandong Provincial Key Laboratory of Animal Biotechnology and Disease Control and Prevention, Shandong Agricultural University, Tai'an, Shandong, China. ${ }^{3}$ Shandong Provincial Engineering Technology Research Center of Animal Disease Control and Prevention, Shandong Agricultural University, Tai'an, China.
Received: 29 April 2020 Accepted: 13 June 2020

Published online: 18 August 2020

\section{References}

1. Lunney JK, Fang Y, Ladinig A, Chen N, Li Y, Rowland B, Renukaradhya GJ (2016) Porcine Reproductive and Respiratory Syndrome Virus (PRRSV): pathogenesis and interaction with the immune system. Annu Rev Anim Biosci 4:129-154

2. Neumann EJ, Kliebenstein JB, Johnson CD, Mabry JW, Bush EJ, Seitzinger AH, Green AL, Zimmerman JJ (2005) Assessment of the economic impact of porcine reproductive and respiratory syndrome on swine production in the United States. J Am Vet Med Assoc 227:385-392

3. Kuhn JH, Lauck M, Bailey AL, Shchetinin AM, Vishnevskaya TV, Bao Y, Ng TF, LeBreton M, Schneider BS, Gillis A, Tamoufe U, Diffo Jle D, Takuo JM, Kondov NO, Coffey LL, Wolfe ND, Delwart E, Clawson AN, Postnikova E, Bollinger L, Lackemeyer MG, Radoshitzky SR, Palacios G, Wada J, Shevtsova ZV, Jahrling PB, Lapin BA, Deriabin PG, Dunowska M, Alkhovsky SV, Rogers J, Friedrich TC, O'Connor DH, Goldberg TL (2016) Reorganization and expansion of the nidoviral family Arteriviridae. Arch Virol 161:755-768

4. Allende R, Lewis TL, Lu Z, Rock DL, Kutish GF, Ali A, Doster AR, Osorio FA (1999) North American and European porcine reproductive and respiratory syndrome viruses differ in non-structural protein coding regions. J Gen Virol 80(Pt 2):307-315 
5. Nelsen CJ, Murtaugh MP, Faaberg KS (1999) Porcine reproductive and respiratory syndrome virus comparison: divergent evolution on two continents. J Virol 73:270-280

6. Johnson CR, Griggs TF, Gnanandarajah J, Murtaugh MP (2011) Novel structural protein in porcine reproductive and respiratory syndrome virus encoded by an alternative ORF5 present in all arteriviruses. J Gen Virol 92:1107-1116

7. Fang Y, Treffers EE, Li Y, Tas A, Sun Z, van der Meer Y, de Ru AH, van Veelen PA, Atkins JF, Snijder EJ, Firth AE (2012) Efficient -2 frameshifting by mammalian ribosomes to synthesize an additional arterivirus protein. Proc Natl Acad Sci USA 109:E2920-E2928

8. Snijder EJ, Kikkert M, Fang Y (2013) Arterivirus molecular biology and pathogenesis. J Gen Virol 94:2141-2163

9. Fang Y, Snijder EJ (2010) The PRRSV replicase: exploring the multifunctionality of an intriguing set of nonstructural proteins. Virus Res 154:61-76

10. Tian X, Lu G, Gao F, Peng H, Feng Y, Ma G, Bartlam M, Tian K, Yan J, Hilgenfeld R, Gao GF (2009) Structure and cleavage specificity of the chymotrypsin-like serine protease (3CLSP/nsp4) of Porcine Reproductive and Respiratory Syndrome Virus (PRRSV). J Mol Biol 392:977-993

11. Han J, Rutherford MS, Faaberg KS (2009) The porcine reproductive and respiratory syndrome virus nsp2 cysteine protease domain possesses both trans- and cis-cleavage activities. J Virol 83:9449-9463

12. Ziebuhr J, Snijder EJ, Gorbalenya AE (2000) Virus-encoded proteinases and proteolytic processing in the Nidovirales. J Gen Virol 81:853-879

13. Frias-Staheli N, Giannakopoulos NV, Kikkert M, Taylor SL, Bridgen A, Paragas J, Richt JA, Rowland RR, Schmaljohn CS, Lenschow DJ, Snijder EJ, Garcia-Sastre A, Virgin HWt (2007) Ovarian tumor domain-containing viral proteases evade ubiquitin- and ISG15-dependent innate immune responses. Cell Host Microbe 2:404-416

14. Han J, Rutherford MS, Faaberg KS (2010) Proteolytic products of the porcine reproductive and respiratory syndrome virus nsp2 replicase protein. JVirol 84:10102-10112

15. Sun Z, Li Y, Ransburgh R, Snijder EJ, Fang Y (2012) Nonstructural protein 2 of porcine reproductive and respiratory syndrome virus inhibits the antiviral function of interferon-stimulated gene 15. JVirol 86:3839-3850

16. Bester SM, Daczkowski CM, Faaberg KS, Pegan SD (2018) Insights into the porcine reproductive and respiratory syndrome virus viral ovarian tumor domain protease specificity for ubiquitin and interferon stimulated gene product 15. ACS Infect Dis 4:1316-1326

17. Sun Z, Chen Z, Lawson SR, Fang Y (2010) The cysteine protease domain of porcine reproductive and respiratory syndrome virus nonstructural protein 2 possesses deubiquitinating and interferon antagonism functions. J Virol 84:7832-7846

18. Shen S, Kwang J, Liu W, Liu DX (2000) Determination of the complete nucleotide sequence of a vaccine strain of porcine reproductive and respiratory syndrome virus and identification of the Nsp2 gene with a unique insertion. Arch Virol 145:871-883

19. Fang Y, Kim DY, Ropp S, Steen P, Christopher-Hennings J, Nelson EA, Rowland RR (2004) Heterogeneity in Nsp2 of European-like porcine reproductive and respiratory syndrome viruses isolated in the United States. Virus Res 100:229-235

20. Yoshii M, Okinaga T, Miyazaki A, Kato K, Ikeda H, Tsunemitsu H (2008) Genetic polymorphism of the nsp2 gene in North American typeporcine reproductive and respiratory syndrome virus. Arch Virol 153:1323-1334

21. Ji G, Li Y, Tan F, Zhuang J, Li X, Tian K (2016) Complete genome sequence of an NADC30-like strain of porcine reproductive and respiratory syndrome virus in China. Genome Announc 4:e00303-16

22. Zhou L, Wang Z, Ding Y, Ge X, Guo X, Yang H (2015) NADC30-like strain of porcine reproductive and respiratory syndrome virus, China. Emerg Infect Dis 21:2256-2257

23. Wang T, Wang X, Li XA, Nie L, Zhang M, Liu S, Zhao X, Shang Y, Zhou EM, Hiscox JA, Xiao Y (2015) Intranasal inoculation of sows with highly pathogenic porcine reproductive and respiratory syndrome virus at midgestation causes transplacental infection of fetuses. Vet Res 46:142

24. Li Y, Ji G, Wang J, Tan F, Zhuang J, Li X, Tian K (2016) Complete genome sequence of an NADC30-like porcine reproductive and respiratory syndrome virus characterized by recombination with other strains. Genome Announc 4:e00330-16
25. Zhao K, Ye C, Chang XB, Jiang CG, Wang SJ, Cai XH, Tong GZ, Tian ZJ, Shi $M, A n$ TQ (2015) Importation and recombination are responsible for the latest emergence of highly pathogenic porcine reproductive and respiratory syndrome virus in China. J Virol 89:10712-10716

26. Zhang X, Li Y, Xiao S, Yang X, Chen X, Wu P, Song J, Ma Z, Cai Z, Jiang $M$, Zhang $Y$, Yang $Y$, Zhang Z, Zhou Z, Sheng J, Wang H (2019) High-frequency mutation and recombination are responsible for the emergence of novel porcine reproductive and respiratory syndrome virus in northwest China. Arch Virol 164:2725-2733

27. Su J, Zhou L, He B, Zhang X, Ge X, Han J, Guo X, Yang H (2019) Nsp2 and GP5-M of porcine reproductive and respiratory syndrome virus contribute to targets for neutralizing antibodies. Virol Sin 34:631-640

28. Song J, Gao P, Kong C, Zhou L, Ge X, Guo X, Han J, Yang H (2019) The nsp2 hypervariable region of porcine reproductive and respiratory syndrome virus strain JXwn06 is associated with viral cellular tropism to primary porcine alveolar macrophages. J Virol 93:e01436-19

29. Kopito RR (2000) Aggresomes, inclusion bodies and protein aggregation. Trends Cell Biol 10:524-530

30. Schubert U, Anton LC, Gibbs J, Norbury CC, Yewdell JW, Bennink JR (2000) Rapid degradation of a large fraction of newly synthesized proteins by proteasomes. Nature 404:770-774

31. Park Y, Park J, Kim YK (2018) Crosstalk between translation and the aggresome-autophagy pathway. Autophagy 14:1079-1081

32. Heath CM, Windsor M, Wileman T (2001) Aggresomes resemble sites specialized for virus assembly. J Cell Biol 153:449-455

33. Banerjee I, Miyake Y, Nobs SP, Schneider C, Horvath P, Kopf M, Matthias P, Helenius A, Yamauchi Y (2014) Influenza A virus uses the aggresome processing machinery for host cell entry. Science 346:473-477

34. Wileman T (2006) Aggresomes and autophagy generate sites for virus replication. Science 312:875-878

35. Wileman T (2007) Aggresomes and pericentriolar sites of virus assembly: cellular defense or viral design? Annu Rev Microbiol 61:149-167

36. Thoreen CC, Sabatini DM (2004) Huntingtin aggregates ask to be eaten. Nat Genet 36:553-554

37. Lamark T, Johansen $T$ (2012) Aggrephagy: selective disposal of protein aggregates by macroautophagy. Int J Cell Biol 2012:736905

38. Xiao Y, Wu W, Gao J, Smith N, Burkard C, Xia D, Zhang M, Wang C, Archibald A, Digard P, Zhou EM, Hiscox JA (2016) Characterization of the interactome of the porcine reproductive and respiratory syndrome virus nonstructural protein 2 reveals the hyper variable region as a binding platform for association with 14-3-3 proteins. J Proteome Res 15:1388-1401

39. Cao S, Cong F, Tan M, Ding G, Liu J, Li L, Zhao Y, Liu S, Xiao Y (2019) 14-3-3epsilon acts as a proviral factor in highly pathogenic porcine reproductive and respiratory syndrome virus infection. Vet Res 50:16

40. Li S, Zhou A, Wang J, Zhang S (2016) Interplay of autophagy and apoptosis during PRRSV infection of Marc145 cell. Infect Genet Evol 39:51-54

41. Sun MX, Huang L, Wang R, Yu YL, Li C, Li PP, Hu XC, Hao HP, Ishag HA, Mao $X$ (2012) Porcine reproductive and respiratory syndrome virus induces autophagy to promote virus replication. Autophagy 8:1434-1447

42. Liu Q, Qin Y, Zhou L, Kou Q, Guo X, Ge X, Yang H, Hu H (2012) Autophagy sustains the replication of porcine reproductive and respiratory virus in host cells. Virology 429:136-147

43. Chen Q, Fang L, Wang D, Wang S, Li P, Li M, Luo R, Chen H, Xiao S (2012) Induction of autophagy enhances porcine reproductive and respiratory syndrome virus replication. Virus Res 163:650-655

44. Wang X, Qiu H, Zhang M, Cai X, Qu Y, Hu D, Zhao X, Zhou E, Liu S, Xiao Y (2015) Distribution of highly pathogenic porcine reproductive and respiratory syndrome virus (HP-PRRSV) in different stages of gestation sows: HP-PRRSV distribution in gestation sows. Vet Immunol Immunopathol 166:88-94

45. Wong ES, Tan JM, Soong WE, Hussein K, Nukina N, Dawson VL, Dawson TM, Cuervo AM, Lim KL (2008) Autophagy-mediated clearance of aggresomes is not a universal phenomenon. Hum Mol Genet 17:2570-2582

46. Chan YK, Gack MU (2016) A phosphomimetic-based mechanism of dengue virus to antagonize innate immunity. Nat Immunol 17:523-530

47. Wang G, Yu Y, Tu Y, Tong J, Liu Y, Zhang C, Chang Y, Wang S, Jiang C, Zhou EM, Cai X (2015) Highly pathogenic porcine reproductive and respiratory syndrome virus infection induced apoptosis and autophagy in thymi of infected piglets. PLoS One 10:e0128292 
48. Wong E, Bejarano E, Rakshit M, Lee K, Hanson HH, Zaarur N, Phillips GR, Sherman MY, Cuervo AM (2012) Molecular determinants of selective clearance of protein inclusions by autophagy. Nat Commun 3:1240

49. El-Khoury V, Pierson S, Szwarcbart E, Brons NH, Roland O, CherrierDe Wilde S, Plawny L, Van Dyck E, Berchem G (2014) Disruption of autophagy by the histone deacetylase inhibitor MGCD0103 and its therapeutic implication in B-cell chronic lymphocytic leukemia. Leukemia 28:1636-1646

50. Brockhaus K, Plaza S, Pintel DJ, Rommelaere J, Salome N (1996) Nonstructural proteins NS2 of minute virus of mice associate in vivo with 14-3-3 protein family members. J Virol 70:7527-7534

51. Riedl W, Acharya D, Lee JH, Liu G, Serman T, Chiang C, Chan YK, Diamond MS, Gack MU (2019) Zika virus NS3 mimics a cellular 14-3-3-binding motif to antagonize RIG-I- and MDA5-mediated innate immunity. Cell Host Microbe 26(493-503):e6

52. Pei Z, Harrison MS, Schmitt AP (2011) Parainfluenza virus $5 \mathrm{~m}$ protein interaction with host protein 14-3-3 negatively affects virus particle formation. J Virol 85:2050-2059
53. Kino T, Gragerov A, Valentin A, Tsopanomihalou M, Ilyina-Gragerova G, Erwin-Cohen R, Chrousos GP, Pavlakis GN (2005) Vpr protein of human immunodeficiency virus type 1 binds to 14-3-3 proteins and facilitates complex formation with Cdc25C: implications for cell cycle arrest. J Viro 79:2780-2787

54. Provost C, Hamonic G, Gagnon CA, Meurens F (2017) Dual infections of CD163 expressing NPTr epithelial cells with influenza A virus and PRRSV. Vet Microbiol 207:143-148

55. Wensvoort G, Terpstra C, Pol JM, ter Laak EA, Bloemraad M, de Kluyver EP, Kragten C, van Buiten L, den Besten A, Wagenaar F et al (1991) Mystery swine disease in The Netherlands: the isolation of Lelystad virus. Vet Q 13:121-130

\section{Publisher's Note}

Springer Nature remains neutral with regard to jurisdictional claims in published maps and institutional affiliations.
Ready to submit your research? Choose BMC and benefit from:

- fast, convenient online submission

- thorough peer review by experienced researchers in your field

- rapid publication on acceptance

- support for research data, including large and complex data types

- gold Open Access which fosters wider collaboration and increased citations

- maximum visibility for your research: over $100 \mathrm{M}$ website views per year

At BMC, research is always in progress.

Learn more biomedcentral.com/submissions 